\title{
Cataloging Problems and Research Libraries
}

The following statements were presented to the Association of Research Libraries at their Chicago meeting, December 29, I94I, held in conjunction with the Midwinter Conference of the American Library Association. Miss Root is president of the Division of Cataloging and Classification of the A.L.A. and Mr. Mumford is chief of the Preparations Division of the New York Public Library.

PART I

$\mathrm{T}$ He Preliminary AmErican SECOND EDITION of the A.L.A. Catalog Rules has been available for three months and has been diligently studied by individual catalogers, by catalog departments, and regional catalog groups, and by some administrators and reference workers. That study will continue and, of course, no one is prepared at this early date to make a final statement. It is possible, however, to see the present trend of opinion and it is that which I shall try briefly to present. As you are aware, the situation is complicated by the fact that after revision had been under way for some years and was nearing completion, it became for the first time very clear first to some administrators and then to a few catalogers that the problem of cataloging costs was extremely serious and that current cataloging theory and practice must be re-examined to see whether there were nonessential elements which could be eliminated. In our study then, we are not merely considering how successfully the code does what it set out to do, which was to expand the old rules to cover types of publications inadequately covered in the 1908 edition and to record the best pre-1940 descriptive cataloging practice with sufficient fulness to meet at least the ordinary needs of the scholarly library. In the light of the pressing demand for economy, a demand made all the more urgent by our entry into the war, we are attempting also to discover those modifications in our cataloging practice which will result in lower processing cost without great impairment in service. Those modifications once found must be incorporated in the code.

You will recall that the code is divided into two parts; the first dealing with entry and heading, the second with the description of the book (transcription of title, imprint, collation, notes). In regard to part one, it is the general opinion that in these days of cooperative cataloging and union catalogs, uniformity in choice of entry is well-nigh essential, though it is admitted that to avoid wholesale recataloging, minor variations in form of entry are permissible for libraries having large amounts of material already cataloged in a manner inconsistent with L.C. and A.L.A. rules. Most of the material in 
the code dealing with choice of entry and form of entry is regarded as satisfactory, though more detailed treatment is needed in a few cases and some unnecessary detail can be eliminated. Some rearrangement is desired but reconsideration is needed of surprisingly few points.

In regard to part two, uniformity in the amount of descriptive detail to be included on the catalog card is now generally recognized to be unnecessary if not indeed undesirable. The amount of detail will and should vary between one library and another and for different types of material within one library. No general rules expressed in a few neat sentences can determine for libraries in general the point of equilibrium between increased cost and decreased usefulness. That point is determined by the balance of many factors which vary with the institution. That being the case, it is an open question $\checkmark$ whether it is necessary or suitable for the A.L.A. to issue rules for descriptive cataloging at all. But, while the amount of detail may vary, there seems to be no good reason for individual decisions as to the language in which we shall record such detail as is to be included on our cards. Standardized notes, abbreviations, etc., are likely to mean a saving in time and so in cost. Many libraries, therefore, will welcome a manual of accepted practice, and L.C. practice would undoubtedly be preferred in view of the widespread use of L.C. cards. It has been suggested, therefore, that part two of the code be replaced by a manual of L.C. practice.

\section{Manual of L.C. Practice}

If we are to have such a manual, whether issued by A.L.A. or by L.C., should it contain the minimum amount of detail or approach the maximum which will be needed by the scholarly library? In the comments which have been received there is surprising unanimity on this point, catalogers and administrators alike stressing the desirability of having fairly full rules available, to be applied with discretion. One cataloger writes "The code should be as complete as it is possible for the committee to make it. Catalogers then can make definite decisions as to which of the rules and usage their libraries with the staff and funds at their disposal can afford to use, or which rules will supply the extent of fulness in cataloging which their type of library needs. The other rules may then be disregarded or used only when the need is definitely felt." Or as an administrator puts it "A great deal of the criticism of the code as being too detailed and legalistic seems to be based upon the idea that every library will have to follow the rules in every detail. My idea of the code is that the committee has labored to bring together and organize in a systematic manner cataloging rules, principles, and practices which already exist and are being followed in varying degrees by libraries of various sorts and sizes. The administrative problem of the extent of simplification of cataloging practices for various kinds of material is something which cannot be covered in a code but must be worked out primarily by the individual libraries. This has been done by libraries working under the old code and the L.C. rules. It seems to me that it can be done even more easily and economically now that the full rules have been put into a form which permits convenient consultation and annotation for a particular library's practice." May I emphasize the fact that there is no indication of an intention on the part of any library to adopt the second part of the 
code, hook, line, and sinker, but the opinion has been expressed again and again that catalogers should have a knowledge of the full rules and simplify to meet the needs of the particular library; that simplified rules are not needed, but that each library should work out its own abridgment to meet its own particular needs. One cataloger goes so far as to add "If a librarian feels that this plan is impracticable, what he needs is a new staff and not a new code."

\section{Decisions on Simplification}

The fact that decisions as to simplification in descriptive cataloging must be made in a particular library on the basis of its particular needs, is generally recognized, but by whom are the decisions to be made? It would not be wise nor practical for catalogers to decide without regard to the needs of the reference and acquisition staffs. Most catalogers are convinced that a prerequisite to the solution of the cataloging problem is finding the answer to the question: For whose use and for what purpose is the catalog made?

For whom is your catalog made and what service is expected from it? Do you need to know from your catalog how many pages there are in a book? Do you need to know whether it contains maps, portraits, diagrams, or genealogical tables? Will your art department be satisfied with cards which do not mention the presence of colored illustrations? This matter of simplification must be regarded as an administrative problem to be worked out by administrative, reference, and cataloging staffs together, in the closest cooperation. May I, for the Division of Cataloging and Classification, express the hope that if conferences to this end have not already begun in your library, you will initiate them on your return. It is our conviction that only by such detailed study on the part of administrators, catalogers, and reference workers together, will any library be able to know its needs and to find a satisfactory answer to its cataloging problem. "Administrators" and "catalogers" in general can never reach a solution which will be satisfactory to all libraries, but a solution for each library, on the basis of its own peculiar needs, can be attained by its own staff working together in this way. Such conferences have already proved their worth in several institutions, as Mr. Mumford is about to tell you, and we are confident that you too will find in them the means of solving your cataloging problem.

\section{PART II}

\section{QUINCY MUMFORD}

The Executive Secretary has suggested that I report to you informally on some developments which have recently taken place at the Library of Congress and at the New York Public Library on the im- portant matter of cataloging rules and practice.

The problem of cataloging cost was well stated by Mr. Metcalf and Dr. Osborn in papers at the Boston Conference. 
Those of you who did not hear Dr. Osborn's paper, entitled "The Crisis in Cataloging," have probably read it in its printed form. It is not my intention to restate in detail the problem which they presented but to mention some steps which have been taken toward attacking that problem.

First, a word about the Library of Congress. Miss Root has mentioned the amount of study which has been made on the new code by individuals and by regional catalogers' groups. In discussions of these groups on the effects of the code on cataloging costs, the question has been asked: "What is the attitude of the Library of Congress? Does it intend to simplify its rules and practices?" I should like to say that the Library of Congress is very keenly conscious of the high cost of cataloging and is eager to cooperate with other libraries in working towards a common solution. It has been faced for a long time with accumulated arrearages of unprocessed material and with the needs of outside libraries to obtain cards more promptly. The report of the librarians' committee and the resulting reorganization in the Processing Division have served to focus attention upon the necessity of finding ways to increase production and to reduce costs in the cataloging process. The new A.L.A. code has provided a basis for the examination of present rules and practices. As Miss Root has suggested, it is not a matter which the cataloging divisions alone can settle. Since the cataloging policy of the library concerns vitally the reference and acquisition divisions, it becomes a general administrative problem. As a step towards a solution, in October, a questionnaire drawn up by the chief of the Descriptive Cataloging Division was submitted to the Acquisition and Refer- ence Divisions in an effort to find out what cataloging information is essential to the proper performance of the respective functions of these divisions. The questionnaire has been followed up by conferences and discussions with those in charge of the reference and acquisition work. There is no doubt that the Library of Congress is ready to make changes in its practices as far as its own needs will permit. No final decisions have been made but the conferences and discussions indicate that considerable simplifications can be accomplished.

\section{At New York Public Library}

At the New York Public Library, a thorough examination of the catalog and its use has been going on. Because of diminishing income, the library has felt the need for retrenchment to some extent in its processing activities. With this necessity in mind, a committee was appointed early in the fall to study the situation and make recommendations. The committee has consisted of the chief of the preparation division, the chief cataloger, an assistant from the administrative office and one from the general reference service, and the chief of the largest subject division. This committee has been meeting once or twice a week during the fall in an effort to determine just what kind of information is most essential in the library's catalogs and what can be eliminated with the least effect on the reference service and with appreciable savings in cost. For a number of years, efforts have been made there to effect some economy in cataloging by giving briefer treatment to certain types of material. For instance, directories and trade catalogs have been arranged in alphabetic files without formal cataloging; pamphlets of subject interest 
only have been bound together and cataloged only under subject. It has been possible at times to group material together and to make a checklist only for it. In such cases, a statement is placed in the catalog showing that the library has the material and how to obtain it. The committee, now engaged in studying further ways of making economies, is seeking to find, first, other types or forms of cataloging which can be reduced or eliminated ; and second, to find ways of shortening the cataloging operation on material which requires regular cataloging treatment. The findings of the committee are still in a tentative stage but enough progress has been made to demonstrate the value of this kind of collaboration between the administrative, reference, and cataloging staffs. It is believed that appreciable savings can be effected without detracting seriously from the value of the catalog.

\section{Informal Conference}

In order to provide a basis for agreement on a simplified procedure which the Library of Congress might adopt and which might serve libraries throughout the country, late in November the Descriptive Cataloging Division in the $\mathrm{Li}$ brary of Congress sponsored an informal conference between representatives of Harvard University, the Columbia University Library School, the New York Public Library, and the Library of Congress. Members of the group included expert catalogers, as well as members with reference and administrative experience. These representatives met for two days in New York and discussed cataloging practices which might be shortened or eliminated. In every instance, the effect of such action upon the acquisition and reference work of libraries was considered.
The results of this conference were highly gratifying. The group was almost in complete accord on points where simplification can be made.

You may ask what are some of the changes which can be made and which will bring about savings. Time does not permit a detailed account of these points here, but I should like to make a general statement on the question. The general principles on which we have been proceeding are:

\section{Possible Changes}

First: To reduce as far as possible the recording of information which requires extensive research on the part of the cataloger. Lengthy searching to find the dates of birth and death and full name of a modern author where there is no conflict in the catalog is an example. Searching to establish the date of publication of an unimportant modern book would be another example. It is likely that other libraries will be able to go further than the Library of Congress in reducing work of this kind since other libraries depend somewhat upon the research of the Library of Congress, and frequent reprinting of cards would be necessary if no research were done. I think, however, it may be possible for the Library of Congress to reduce substantially the amount of research.

Second: To shorten or omit entirely certain kinds of information in the transcription of the title page. Titles may be shortened and imprints simplified.

Third: To eliminate as far as possible rules and practice which constitute debatable and time-consuming points for the cataloger. This latter category applies particularly to collation and notes. It is hard to realize how much time goes into the recording of pagination and illustra- 
tions under the present practice of the Library of Congress. There is no doubt that simple notations of these items will result in a considerable saving of time.

Additional time and study is needed at the Library of Congress on these points, but, as I have indicated, it seems certain that some simplifications can be made. It is our belief that a simplified card which will serve the needs of the Library of Congress will be adequate for other libraries. In fact, many libraries may be able to simplify their practices farther than the Library of Congress can do. When specific details have become more settled, you will be informed of the changes which the Library of Congress proposes to make. In the meantime, as Miss Root has suggested, it will be extremely helpful if individual librarians will confer with their acquisition, reference, and cataloging staffs and seek to determine what types of information are needed in the catalogs of their respective libraries. Such study is essential for the formulation of a policy in the individual library and will greatly assist the Library of Congress in modifying its own practice.

\section{Way to the Future: Cooperative and Centralized Cataloging}

\section{(Continued from page I62)}

separate unit coordinated with the cooperative work there is subject to consideration by representatives of cooperating libraries and of the Library of Congress. The Librarian of Congress has on several occasions expressed his interest in the extension of cooperative cataloging.

\section{Cooperative Work the Practical Solution of the Cataloging Problem}

To sum up, the practical solution of the cataloging problem, assuming that the catalog is not to be abolished altogether as has been recently, perhaps not too se- riously, proposed by some administrators, or reduced to a simple author list, lies in cooperative work. Cooperative cataloging should not confine itself to one particular method. Libraries should continue to make use of the cataloging product of the Library of Congress and amplify the scope of its work by some auxiliary form of either centralized or distributive cooperation. If all libraries find the H. W. Wilson Company's product adequate, the Library of Congress could perhaps be relieved of the burden of supplying cards for the most popular books. 